\title{
AN OPERATIONALIZATION FOR COLLECTING EXPERTS' OPINIONS ON THE DESIGN OF AN E-DELIBERATION TOOL
}

\author{
Alexandra Gheondea-Eladi ${ }^{1,2}$, Mark Verhijde ${ }^{3}$, Mousa Albashrawi ${ }^{4}$, \\ Vassilis Tsakanikas ${ }^{5}$ and Vassilis Triantafillou ${ }^{5}$ \\ ${ }^{1}$ Rovira $i$ Virgili University, Faculty of Business and Economics, Spain \\ ${ }^{2}$ Romanian Academy, Research Institute for Quality of Life, Romania \\ ${ }^{3}$ Estonian School, Netherlands \\ ${ }^{4}$ KFUPM Business School, King Fahd University of Petroleum \& Minerals, Saudi Arabia \\ ${ }^{5}$ University of Peloponnese, Electrical and Computer Engineering, Greece
}

\begin{abstract}
Background: In practice, e-democracy is based on two pillars - one is e-participation and the other is e-voting. The development of e-government is a major technological achievement allowing citizens to participate equally in the political process. E-government and E-Participation, as a part of e-democracy, encompass social, economic and cultural conditions that enable the free and equal practice of political self-determination. Information and Communications Technology can be a powerful tool to increase the quality of public policy, citizens understanding of public policy issues and their participation in government policy making.

International Relevance: According to the Government Online International Network, governments around the globe are actively promoting online consultations in order to strengthen democracy and development (Poland, 2001). Yet, a major citizens' concern about the usage of e-democracy tools, and more specifically, e-deliberation apparatuses is data security and confidentiality. Within a process of expressing political opinions, citizens need to be reassured that the collected data will only be used for the intended purposes and the possibility of data leakage will be minimized. While mainstream technology (firewalls, encrypted databases, etc.) can provide quite a substantial level of security, data confidentiality issues arise every day.

Aim: The aim of this paper is to report on the first phase of an ongoing research aimed at designing, developing and testing an e-deliberation tool. This first phase represents the collection of experts' opinions for the design of an e-deliberation tool through literature review, survey with experts and expert group workshops. We present the operationalization of a series of criteria for e-deliberation tool comparison. This operationalization will be used to build a questionnaire for experts in the field of e-deliberation and to guide data collection though a series of expert group workshops.

Methodology: A review of the literature has been performed in order to select relevant criteria and variables which will be used to build a questionnaire for experts in the field of e-deliberation. We report on the operationalization of these variables and criteria.
\end{abstract}

Impact: The results of this research will be used to further inform e-deliberation tool development.

\section{KEYWORDS}

E-deliberation, Revitalization of Public Space, Methodology, Experts' Opinions

\section{INTRODUCTION}

Offline democracy has been implemented in many societies around the world for centuries, along with other forms of political organization. The various forms of manifesting democracy have exhibited a series of unintended and rather difficult to tackle vulnerabilities, like barriers to participation, delayed self-expression in large-scale societies, limited resources for developing and processing census-size large-scale opinion polls, corruption and so on (Gastil \& Richards, 2013; Sæbø, Rose, \& Molka-Danielsen, 2010). Based on technological advances and in response to these challenges, researchers have proposed a shift of the democratic forum to the virtual environment (Lavin \& Insua, 2010; Liston, Harris, \& O'Toole, 2013) where access restrictions are limited to internet access and processing resources are enhanced by technological innovation. 
In this context, e-democracy entails two major components: e-participation and e-voting (Macintosh, 2004; Wallter, 2001) and aims to encompass social, economic and cultural conditions that enable the free and equal practice of political self-determination with the extra benefit of high security, confidentiality and transparency. E-governance reflects an institutionalized form of e-democracy which includes various state services (taxation, residency and population ledgers, etc.) with or without e-participation and e-voting.

One of the defining components of democracy is the democratic forum. With technological innovations, it is slowly being transferred into practice in the form of various e-deliberation platforms, tools and facilities (Participedia, D-Cent, Global Citizen). But researchers have already pointed out the importance of design for facilitating deliberation (Wright \& Street, 2007). For this reason, the main assumption of this paper is that the design and development of such e-deliberation tools, may be informed by literature reviews or by pooling opinions of experts on specific aspects of their development. Such aspects include moderation, power sharing, dealing with constructive and destructive social roles which appear in group deliberation, etc. and have all been studied in the behavioural and social sciences.

In this paper we describe a sociological operationalization of concepts for building a questionnaire (available here https://forms.gle/5u7h1k1jbtPCX5h6A) aimed at experts in e-deliberation and e-governance. In the first part we select the most relevant concepts for comparing e-deliberation tools based on a disciplinary (section 2.1) and interdisciplinary (section 2.2) literature review. In the second part we present the operationalizaiton of the selected concepts. The conclusions of this work have been materialized in the aforementioned online questionnaire. The final goal is to incorporate these conclusions and the results of the questionnaire analysis to an already proposed e-deliberation system (Triantafyllou, Tsakanikas, Asimakopoulos, \& Christodoulopoulos, 2019).

\section{MATERIALS AND METHODS}

E-deliberation tools are technological systems which facilitate debates with a variable structuring degree and preference aggregation for large groups of citizens. They are also called public online deliberation systems and may include various service modules, like: issue preparation, proposal qualification, deliberation and proposal acceptance/drop-off (Triantafyllou et al., 2019), or Problem structuring, Explanatory, Arbitration management, Preference modelling, Participatory process control, Information resource management, Debate management, Negotiation management, and Voting management (French, Rios Insua, \& Ruggeri, 2007). However, the problems encompassed by these building blocks of e-deliberation tools have been extensively studied offline within behavioural and social sciences. In this section we provide the results of a literature review aimed at formulating criteria for evaluating the building blocks of e-deliberation tools. It is important to mention that the results of this work, as well as the conclusions that will be derived from the questionnaire analysis will be incorporated to an already proposed e-deliberation system (Triantafyllou et al., 2019). Actually, the main research aim of this manuscript is to provide a structured process of acquiring the most relevant aspects which should be addressed by an e-deliberation tool.

\subsection{Selecting e-Deliberation Tool Criteria}

The literature review has been performed as a structured search with the following key-words: "e-deliberation", "online deliberation", "e-democracy", "online democracy”, "participation”, "public deliberation", "public engagement", "public empowerment", with logical combinations of these using Boolean operators AND, OR, performed on SAGE Journals database and Google Scholar. The choice of this particular search engine and database was based on access restrictions during the time of this review. An example or search combination is ("e-deliberation" OR "online deliberation") AND ("e-democracy" OR "online democracy") AND ("participation" OR "public participation") and yielded 1350 results out of which search results have been reviewed until three consecutive pages yielded no relevant results. Searches were performed in different days on a period of 8 months. Out of all searchers performed, 70 relevant papers have been selected for review. During this process, we excluded papers that did not mention any criteria about setting up an e-deliberation tool, and purposefully selected those which provided criteria transferable into known technology, as it is currently available at the time when this paper was written from the point of view of the authors. From the reviewed papers, a list of potential criteria relevant for e-deliberation tool evaluation has been selected 
(Table 1). In Table 1, most of the selected criteria have been directly discussed in the references indicated, while others were indirectly derived from sources on decision-making and group decision-making. For simplicity, in this table we do not mention papers that suggested similar criteria with those already reviewed.

Table 1. Selected e-deliberation tool criteria

\begin{tabular}{|c|c|c|}
\hline Concept Criterion & Variable Name & Source of Def \\
\hline \multirow[t]{2}{*}{ Public Engagement } & Public Engagement Degree & Rowe \& Frewer (2005) \\
\hline & Public Engagement Degree & $\begin{array}{l}\text { International Association } \\
\text { for Public Participation (2014) }\end{array}$ \\
\hline Democracy & Democracy Type & $\begin{array}{l}\text { Cini (2011); Lavin \& Insua } \\
\text { (2010) }\end{array}$ \\
\hline \multirow[t]{5}{*}{ Quality of Deliberation } & Quality of discussion & Jonsson \& Astrom (2014) \\
\hline & Type of deliberation & Jonsson \& Astrom (2014) \\
\hline & Anonymity & Jonsson \& Astrom (2014) \\
\hline & Degree of Moderation & Jonsson \& Astrom (2014) \\
\hline & Face-to-Face vs. online & Jonsson \& Astrom (2014) \\
\hline \multirow[t]{4}{*}{ Individual Gains } & Opinion Change (Public) & Jonsson \& Astrom (2014) \\
\hline & Opinion Change (State) & Jonsson \& Astrom (2014) \\
\hline & Knowledge & Jonsson \& Astrom (2014) \\
\hline & Efficacy & Jonsson \& Astrom (2014) \\
\hline Effects on policy & Policy connection & Jonsson \& Astrom (2014) \\
\hline Content consensus & Deliberation process facilitates content consensus & Gheondea-Eladi (2017) \\
\hline Process consensus & Deliberation process facilitates process consensus & Gheondea-Eladi (2017) \\
\hline Type of System & Type of deliberative system & Lavin \& Insua (2010) \\
\hline $\begin{array}{c}\text { Transparency of the } \\
\text { decision-making system }\end{array}$ & Transparency of the decision-making system & Lavin \& Insua (2010) \\
\hline \multirow[t]{9}{*}{ Participatory process } & Is the system part of a larger participatory process & Lavin \& Insua (2010) \\
\hline & Scope & French et al. (2007) \\
\hline & Financing & French et al. (2007) \\
\hline & Owner & French et al. (2007) \\
\hline & Type of interactions facilitated by the system & French et al. (2007) \\
\hline & Access limitations & French et al. (2007) \\
\hline & Problem structuring phase & Lavin \& Insua (2010) \\
\hline & Social role in debate & Fujimoto (2016) \\
\hline & Preference aggregation method & Lavin \& Insua (2010) \\
\hline
\end{tabular}

In Table 2, each variable selected has been operationalized into questions, as suggested by the source indicated in Table 1.

\subsection{A Revitalization of Participation in Public Dialogue}

In this section, we argue that e-democracy can be regarded as s process of revitalization of the public space into the virtual space. Therefore we take a look at previous research in revitalization of public spaces and argue, in line with Turala \& Sikora-Fernandez (2014), that the purpose of e-deliberation is threefold:

- Restructuring public dialogue based on the social and economic dimensions

- Rehabilitation and regeneration of public dialogue by replicating parts of past public dialogue

- Revitalization of public dialogue by "renovating", "modernizing" and "revalorization" of the public dialogue (adapted from Turala \& Sikora-Fernandez, 2014: 242).

Furthermore, we discuss the ways in which these three goals can be achieved, namely:

1. scaling deliberation by providing systematic connections between different local communities in multiple ways: incrementalism, interscalar links and also learning from local qualitative knowledge of neighbourhoods;

2. managing deliberation by providing tools to generate shared meaning though: recurrent meetings, feed-back loops and structured communication;

3. ensuring the practice of participation through empowering citizens to reflect and improve their own deliberation practice and the tools required to do so. 
The philosophic concepts around the revitalization of public spaces (Gheondea-Eladi, 2015) may be of particular interest for implementing deliberative online tools. For example, in revitalization, scaling participatory practice is performed in three main ways (Bradford, 2013):

- Incrementalism: This translates into EDT implementation in small communities and additively constructing large-scale e-deliberation based on small-scale communities, as units;

- Interscalar links: This translates into replicating at large-scale only the aspects considered essential in small-scale EDTs;

- Learning from the local: This translates into implementing elements of qualitative analysis, like tags and categories into EDTs constructed based on an in-depth understanding of small-scale e-deliberation.

Another issue in scaling participation processes from small communities to large societies is finding systematic connections between different local communities. So far, researchers have adopted different approaches. For example, Bradford (2013) considered the diversity between local communities and provided consultations with the community only in the pilot test, while Seta (2008) took into consideration the consensus between local communities.

Participation also entails the management of public dialogue and its main dangers: imposing top-down agenda, skewed representation of bottom-up diversity and blocking emergence of innovative solutions. One practical example is provided by Elwood's (2002) 2 phase community dialogue which allowed top-down objectives to be contested and improved. As an unintended consequence, only neighbourhoods which were in "the most prosperous conditions" and those "facing the most severe problems" (p. 128) have deviated from the original objectives.

Based on this analysis, we conclude that it will be useful to investigate participatory mechanisms which provide the best manner in which shared meaning can be constructed as opposed to only shared language. Based on the projects analysed in this subsection (Bradford, 2013; Elwood, 2002; Seta, 2008) we propose the investigation of:

- $\quad$ Recurrent meetings at online community level;

- $\quad$ Ensuring a feed-back loop between all levels of public hierarchy;

- $\quad$ Structured communication within deliberation.

Another feature of public dialogue is empowerment. Townsend (2014) defines empowerment as:

- A chance to "have a say about what is important";

- A chance to do things that are considered important;

- A chance to change things that do not seem important;

On the other hand, public dialogue is expected to employ the benefits of the Hawthorn effect (observer effect) (Mayo, 1945) and avoid its side-effects. 
Table 2. Definitions and values of variables

\begin{tabular}{l|l}
\hline Variable Name & Definition \\
\hline Public Engagement Degree & $\begin{array}{l}\text { Should the public be involved in the governing system through: } \\
\text { passive (via public communication, one way, from State to public, } \\
\text { via different media), quasi-active (via public consultation, one } \\
\text { way, from public to State via a process determined by the state), } \\
\text { e.g. balloting, referendum, petition signing, surveys, etc.) or active } \\
\text { engagement (via public participation, two ways, e.g. deliberative } \\
\text { opinion polls, focus groups, public hearing, citizens panels, etc.)? }\end{array}$ \\
$\begin{array}{l}\text { Should power be shared between the State and Citizens through: } \\
\text { Public information (balanced and objective information to the } \\
\text { public in order for them to understand the current problems of the } \\
\text { State/policy makers), public consultations (obtaining public feed- } \\
\text { back on alternatives or solutions decided by the State). public } \\
\text { involvement (ensuring that public inputs are considered in the } \\
\text { development of alternatives and that feedbacks are provided on } \\
\text { how this has been resolved), public collaboration (public inputs are } \\
\text { adhered to not just the development of alternatives but also the } \\
\text { identification of preferred solutions), public empowerment } \\
\text { (placing the final decision making process in the hands of the } \\
\text { public through certain means like citizen juries, ballots and } \\
\text { delegated decisions)? }\end{array}$
\end{tabular}

\section{Democracy Type}

Quality of discussion

Type of deliberation

Anonymity

Degree of Moderation

Face-to-Face vs. online

Opinion Change (Public)
Should citizens be involved in the e-public sphere through: participatory democracy (every citizen takes part in all the decisions that would affect the quality and conduct of his or her life), deliberative democracy (that the state provides the means by which the public can independently participate in such decisions), proximity democracy (communication exists mainly based on levels of proximity), community development-type democracy (self-management, co-management, co-decisions and empowerment-based management of social problems), public/private partnership-driven democracy (creating solutions for social problems by getting the private and the public sector involved, without the direct input from citizens), neo-corporative democracy (finding solutions for social problems by deliberation at the level of social collectives and associations, like NGOs, unions, businesses, churches and local government, etc.)?

Should deliberation really take place within the system?

What kind of deliberative process should be used within the system?

Are users identified, identifiable or completely anonymous within the system?

To what extent should the deliberation be moderated within the system?

The degree of blend between face-to-face and online deliberation within the system?

The degree to which opinion change should take place on the part of the Public? 


\begin{tabular}{|c|c|}
\hline Opinion Change (State) & $\begin{array}{l}\text { The degree to which opinion change should take place on the part } \\
\text { of the State? }\end{array}$ \\
\hline Knowledge & The degree to which citizens should learn about issues of the state? \\
\hline Efficacy & $\begin{array}{l}\text { The degree to which the deliberation system leads to practical } \\
\text { solutions for social problems? }\end{array}$ \\
\hline Policy connection & $\begin{array}{l}\text { What should be the impact of the system on policy making: } 1 \text {. } \\
\text { informing policy, but deferring decision to the state; } 2 \text {. creating } \\
\text { policy through deliberation, but state votes on it; } 3 \text {. creating public } \\
\text { policy through deliberation, and having the state transform it into } \\
\text { law? }\end{array}$ \\
\hline $\begin{array}{l}\text { Deliberation process facilitates } \\
\text { content consensus }\end{array}$ & $\begin{array}{l}\text { How long should the deliberation phase last such that it is enough } \\
\text { to foster content consensus? }\end{array}$ \\
\hline $\begin{array}{l}\text { Deliberation process facilitates } \\
\text { process consensus }\end{array}$ & $\begin{array}{l}\text { Is there a step in which citizens decide on the process of } \\
\text { deliberation? }\end{array}$ \\
\hline Type of deliberative system & $\begin{array}{l}\text { Should the deliberation system be: question-centric, topic-centric, } \\
\text { debate-centric or argument-centric? }\end{array}$ \\
\hline $\begin{array}{l}\text { Transparency of the decision- } \\
\text { making system }\end{array}$ & What should be the degree of transparency of the decision-system? \\
\hline $\begin{array}{l}\text { Is the system part of a larger } \\
\text { participatory process }\end{array}$ & $\begin{array}{l}\text { The degree to which the system should be part of a larger } \\
\text { participatory process of interactions between authorities, } \\
\text { stakeholders and citizens from the initial exploration of issues of } \\
\text { concern up to the conclusion of the deliberations and resolution of } \\
\text { the matter? }\end{array}$ \\
\hline Scope & Should the scope of the system be local, regional or national? \\
\hline Financing & Should the system be publicly, privately or mixed funded? \\
\hline Owner & $\begin{array}{l}\text { What type of entity should own the system with authority status } \\
\text { over it? }\end{array}$ \\
\hline $\begin{array}{l}\text { Type of interactions facilitated } \\
\text { by the system }\end{array}$ & $\begin{array}{l}\text { What types of interactions should the deliberation system } \\
\text { facilitate: individual and written, dyadic video, group writing, } \\
\text { group video, other }\end{array}$ \\
\hline Access limitations & $\begin{array}{l}\text { What types of access limitations should the system address: e- } \\
\text { literacy, internet connection, blind-and death accessibility, other? }\end{array}$ \\
\hline Problem structuring phase & Should the system include a problem structuring phase? \\
\hline Preference aggregation method & $\begin{array}{l}\text { What kind of preference aggregation method should the system } \\
\text { use? }\end{array}$ \\
\hline
\end{tabular}


However, the literature on empowerment in practice has thus far shown that it is not possible to share power without the practice of participation. This purports a learning process and recurrent practice. Townsend (2014) and Scheer (2012) showed that empowerment is power over ones practice, not power over [something], but power to [do something]. While community participation may lead to the empowerment of the local community (Speer, Peterson, Armstead, \& Allen, 2013: 103), not all projects that involve participation lead to empowerment (Rogers et al., 2007: 785). From this point of view, if Practice means doing for this purpose, in this situation and at this time, in a way that can be repeated by others, reflected upon and improved (Gheondea-Eladi, 2015; Townsend, 2014), then Participation Practice means doing things to facilitate participation, in each relevant situation, as frequent as possible, in a way that can be repeated by others, reflected upon and improved. Thus, e-deliberation tools should provide virtual space and tools not only for participation in dialogue, but also provide separate virtual spaces for reflecting and improving the practice of participation

\section{CONCLUSION}

To sum up, this paper leads to two main conclusions. First, we propose that experts' opinions' can be collected to inform the design and development of e-deliberation tools based on the evaluation of the following variables: Public Engagement Degree, Democracy Type, Quality of discussion, Type of deliberation, Anonymity, Degree of Moderation, Face-to-Face vs. online, Opinion Change (Public), Opinion Change (State), Knowledge, Efficacy, Policy connection, Deliberation process facilitates content consensus, Deliberation process facilitates process consensus, Type of deliberative system, Transparency of the decision-making system, Is the system part of a larger participatory process, Scope, Financing, Owner, Type of interactions facilitated by the system, Access limitations, Problem structuring phase, and Preference aggregation method. Second, based on the reviewed literature on revitalization of public spaces, e-deliberation tools may be envisioned to provide power to change what is done and also the way (how) things are done on issues of public interest. In French, Rios Insua, \& Ruggeri's (2007) terms we propose that the Participatory Process Control Module (p. 218) also contains different features and sub-modules which can be controlled by citizens during the deliberation process. In this way citizens can decide on the tools that are required for them to deliberate on a certain issue. Furthermore, we propose that an e-deliberation tool, as the one proposed by French et al. (2007) also includes virtual space for reflection and feed-back after the deliberation process. Both of these would be included in the kernel sub-system. Last, but not least we suggest that scaling is facilitated in three main ways: by adding input from multiple small-scale deliberation forums (e.g. from multiple communities on the same issue), by organizing large-scale deliberation only on the common links suggested by citizens and groups of citizens and by allowing a fine-grained structure for qualitative analysis and abstraction (e.g. argument-based generalization) based on grass-roots input.

One of the limitations of the operationalization proposed in this paper is that it does not address the variation in participatory culture pertaining to different countries. This variation may be visible within the answers to the Public Engagement questions, if the data is analysed by country. However, in this paper we do not aim to directly address this.

\section{ACKNOWLEDGEMENT}

This research is partially supported by "An Effective Public Deliberation System", a project funded under Research and Innovation Strategies for Smart Specialisation (RIS3) act, region of Western Greece.

\section{REFERENCES}

Bradford, N. (2013). Neighbourhood Revitalization in Canada: Towards Place-Based Policy Solutions. In D. Manley, M. van Ham, N. Bailey, L. Simpson, \& D. Maclennan (Eds.), Neighbourhood Effects or Neighbourhood Based Problems? SE - 8 (pp. 157-176). Springer Netherlands. https://doi.org/10.1007/978-94-007-6695-2_8

Cini, L. (2011). Between Participation and Deliberation: Toward a New Standard for Assessing Democracy? Pavia: online. 
Elwood, S. (2002). Neighborhood revitalization through "collaboration": assessing the implications of neoliberal urban policy at the grassroots. GeoJournal, 58, 121-130.

French, S., Rios Insua, D., \& Ruggeri, F. (2007). e-Participation and Decision Analysis. Decision Analysis, 4(4), $211-226$.

Fujimoto, M. (2016). Team Roles and Hierarchic System in Group Discussion. Group Decision and Negotiation, 25, 585-608.

Gastil, J., \& Richards, R. (2013). Making Direct Democracy Deliberative through Random Assemblies. Politics \& Society, 41(2), 253- 281.

Gheondea-Eladi, A. (2015). Revitalization and Action Research. In D. Bazun \& M. Kwiatkowski (Eds.), Socializing Revitalization (Uspołecznić Rewitalizację). Zielona Gora.

Gheondea-Eladi, A. (2017). What connects us in shared decision-making in health. Rocznik Lubuski, 43(2), 144-160.

International Association for Public Participation. (2014). IAP2's Public Participa tion Spectrum. IAP2 international Federation.

Jonsson, M. E., \& Astrom, J. (2014). The Challenges for Online Deliberation Research: a Literature Review. International Journal of E-Politics, 5(1), 1-5.

Lavin, J. ., \& Insua, D. R. (2010). Participatory processes and instruments. In e-Democracy. A group decision and negotiation perspective (pp. 31-48).

Liston, V., Harris, C., \& O'Toole, M. (2013). Bridging Normative Democratic Theory and Internet Technologies: A Proposal for Scaling Citizen Policy Deliberations. Policy and Internet, 5(4), 1-25.

Macintosh, A. (2004). Characterizing E-Participation in Policy-Making. In Proceedings of the 37th Hawaii International Conference on Systems Science.

Mayo, E. (1945). The human problems of industrial civilization. (4th ed.). New York: Macmillan. Retrieved from https://archive.org/stream/socialproblemsof00mayo/socialproblemsof00mayo_djvu.txt

Rogers, S. E., Teague, G. B., Lichenstein, C., Campbell, J., Lyass, A., Chen, R., \& Banks, S. (2007). Effects of participation in consumer-operated service programs on both personal and organizationally mediated empowerment: Results of multisite study - ProQuest. Journal of Rehabilitation Research and Development, 44(6), 785-800. Retrieved from http://search.proquest.com/docview/215284976/fulltextPDF/912CD4F4A4454AC8PQ/16?accountid=15533

Rowe, G., \& Frewer, L. . (2005). A Typology of public engagement mechanisms. Science, Technology and Human Values, $30(2), 251-290$

Sæbø, Ø., Rose, J., \& Molka-Danielsen, J. (2010). eParticipation: Designing and Managing Political Discussion Forums. Social Science Computer Review, 28(4), 403-426.

Scheer, M. (2012). Are emotions a kind of practice (and is that what makes them have a history)? A Bourdieusian approach to understanding emotion. History and Theory, 51, 193-220.

Seta, F. (2008). Activities of Local Organizations for Downtown Revitalization in Regional Cities. In T. Kidokoro, N. Harata, L. Subanu, J. Jessen, A. Motte, \& E. Seltzer (Eds.), Sustainable City Regions: SE - 9 (Vol. 7, pp. 163-181). Springer Japan. https://doi.org/10.1007/978-4-431-78147-9_9

Speer, P. W., Peterson, A. N., Armstead, T. L., \& Allen, C. T. (2013). The Influence of Participation, Gender and Organizational Sense of Community on Psychological Empowerment: The Moderating Effects of Income - ProQuest. American Journal of Community Psychology, 51, 103-113. Retrieved from http://search.proquest.com/docview/1286931514/fulltextPDF/912CD4F4A4454AC8PQ/8?accountid=15533

Townsend, A. (2014). Weaving the threads of practice and research. In F. Rauch, A. Schuster, T. Stern, M. Pribila, \& A. Townsend (Eds.), Promoting Change through Action Research (pp. 7-22). Rotterdam: Sense Publishers.

Triantafyllou, V., Tsakanikas, V., Asimakopoulos, G., \& Christodoulopoulos, J. (2019). Public Online Deliberation Systems. In Presentation at E-Society Conference. Utrecht.

Turala, M., \& Sikora-Fernandez, D. (2014). Urban Renewal in Warsaw's Commercial Real Estate Market. In E. F. Nozeman \& A. J. Van der Vlist (Eds.), European Metropolitan Commercial Real Estate Markets SE - 9 (pp. 225-250). Springer Berlin Heidelberg. https://doi.org/10.1007/978-3-642-37852-2_9

Wallter, P. (2001). E-government in the service of democracy. A consultation paper on a policy for electronic democracy.

Wright, S., \& Street, J. (2007). Democracy, deliberation and design: the case of online discussion forums. New Media \& Society, 9(5), 849-869. 